\title{
The role of NDI on the failure analysis of an aircraft propeller hub
}

\author{
Iordanis Spyroglou', Angelos Koutsomichalis ${ }^{2, *}$, Panos Stavropoulos ${ }^{2}$, and Nikolaos \\ Roussis $^{1}$ \\ ${ }^{1}$ Electronics Depot Centre-R\&T Centre, Hellenic Air Force, Athens, 16562, Greece \\ ${ }^{2}$ Hellenic Air Force Academy, Laboratory of Materials, TGA 1010, Attica, Greece
}

\begin{abstract}
This paper analyses the causes of an incident in an aircraft propeller hub. The aluminum alloy propeller blade hub was detached from the plane bearing one of its two blades with the other one being jettisoned away. Stereoscopic examination of the fractured hub revealed that it was initially cracked by fatigue, with the crack initiating on the root of the third and fourth spirals and propagating form the inner to the outer. SEM analysis showed that the crack epicentres were created very close or/and on the spiral roots and were attributed to microcracks from corrosion pits and high stress concentration. Non Destructive Inspection was both used on the other side of the hub and the remaining three hubs of the plane and confirmed the presence of cracks similar to those which caused the fatigue failure of the fractured hub but at earliest stage of development.
\end{abstract}

\section{Introduction}

The propeller consists of several blades held in place by a central hub. The propeller hub holds the blades in place and is connected to the engine through a propeller drive shaft and a gearbox. Modern propellers on large turboprop airplanes typically have 4 to 6 blades. Other components typically include the spinner, which creates aerodynamic streamlining over the propeller hub, the bulkhead, which allows the spinner to be attached to the rest of the propeller, the pitch change actuator, to transmit hydraulic energy to rotate the blades in the hub and a source of high pressure oil to supply hydraulic energy to the propeller actuator.

The function of the hub is to fasten the propeller blades to the engine. For most fixedpitch props, the hub is integral to the blades. Constant-speed props need to allow the blades to rotate in the hub. Many different blade retention systems have been used throughout the years, with the more recent designs intended to be longwearing and corrosion resistant. As the fleet ages, it's becoming more common to hear of prop-hub distress in addition to the more prevalent blade maladies. Failures of hubs are comparatively rare. Typically, the hub problems involve cracking prior to failure $[1,2]$ while cases of propeller assembly failure have been reported $[3,4]$. Corrosion pits inside the hub can cause cracks to form when the

\footnotetext{
* Corresponding author: angelos.koutsomichalis@ hafa.haf.gr
} 
hub is subjected to operating stresses. Such incidents are particularly distressing because they are preventable with proper maintenance and overhaul. Prior to failure, a cracked hub or blade retention component may provide a warning with the sudden onset of grease or oil leakage or vibration $[5,6]$.

Non-destructive tests help to understand the condition of the aircraft hub and make the necessary maintenance works which may increase the service life hub. Nondestructive tests used mainly are eddy current inspection, magnetic particle inspection and visual inspection [7-10]. Eddy current NDT can examine large areas very quickly, and it does not require use of coupling liquids. In addition to finding cracks, eddy current can also be used to check metal hardness and conductivity in applications where those properties are of interest, and to measure thin layers of nonconductive coatings like paint on metal parts. Eddy current and ultrasonic testing can be used together as complementary techniques, with eddy current having an advantage for quick surface testing and ultrasonic having better depth penetration. The eddy current instrument plots changes in the impedance amplitude and phase angle, which can be used by a trained operator to identify changes in the test piece. Magnetic particle inspection is a method of locating surface and subsurface discontinuities in ferromagnetic materials. It depends on the fact that when the material or part under test is magnetized, magnetic discontinuities that lie in a direction generally transverse to the direction of the magnetic field will cause a leakage field to be formed at and above the surface of the part. The presence of this leakage field, and therefore the presence of the discontinuity, is detected by the use of finely divided ferromagnetic particles applied over the surface, with some of the particles being gathered and held by the leakage field. This magnetically held collection of particles forms an outline of the discontinuity and generally indicates its location, size, shape, and extent. Magnetic particles are applied over surface dry particles, or as wet particles in a liquid carrier such as water or oil $[11,12]$.

This paper is devoted to the investigation of cracks in aircraft engine hubs and particularly it analyzes the crack finding in hubs which were cracked as the NDI revealed in comparison with a hub that fractured. Analysis is based on Visual Inspection, StereoMicroscopy, Metallography, Chemical Analysis, Scanning Electron Microscopy (SEM) and Energy Dispersive X-ray Spectroscopy (EDS).

\section{Experimental}

A set of hubs from the aero engine were examined. One hub was fractured while three others, not fractured but cracked, were used for in depth analysis of the cracks. A fourth hub was kept intact for use in future NDI examinations as standard.

NDI was used to trace cracks and the cracked hubs were then properly cut around the spotted crack areas in order gradually to reveal the topography of the cracks. Detailed analysis included visual examination, optical and scanning electron microscopy and chemical analysis. The fractured area and the damaged sections of the fractured hub were cleaned ultrasonically and were examined by stereoscope and SEM.

Samples were cut from the hub and were prepared following standard metallographic practice and etched using a chemical reagent for microstructural examination. Kellers agent was used for etching the hub parts. 


\section{Results and discussion}

\subsection{Visual examination}

Three hubs, which had undergone Non Destructive Inspection (NDI), were thoroughly examined. In particular, parts of the hubs, in which NDI had detected cracks, were cut off as seen in Fig.1.

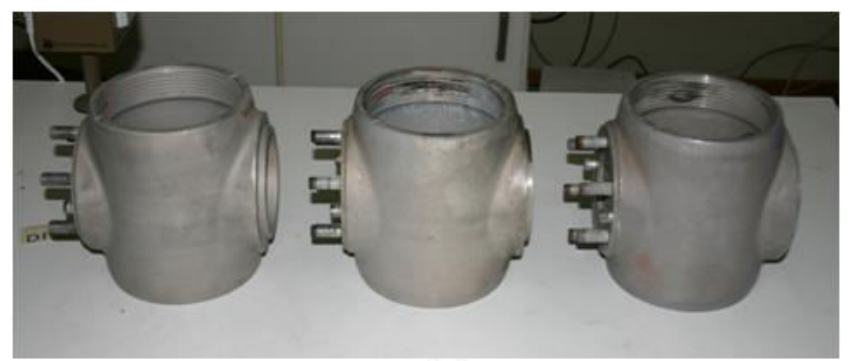

(a)

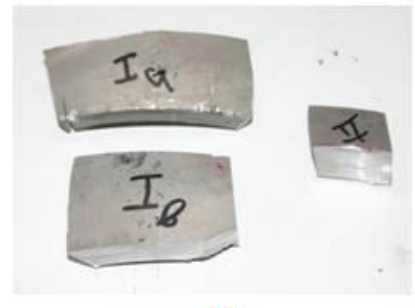

(b)

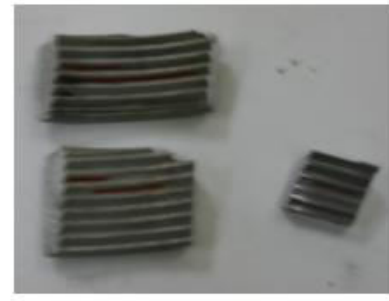

(c)

Fig. 1. (a) View of the hubs (b) outer side of the hubs cut off parts (c) inner side of the hubs (threads) cut off parts for further examination

Fig 2 shows parts of the detected cracks. All the cracks were detected between the threads (in between second and fifth). Further on successive incisions were performed in order to open the cracks (Fig. 2b). It is evident that this is a typical case of fatigue fracture from multiple initiation points in stress concentration areas near the thread root. It is similar in nature to the crack from which caused the failure of the incident, but at earliest stage of development, with a depth of about $0.6 \mathrm{~cm}$. 

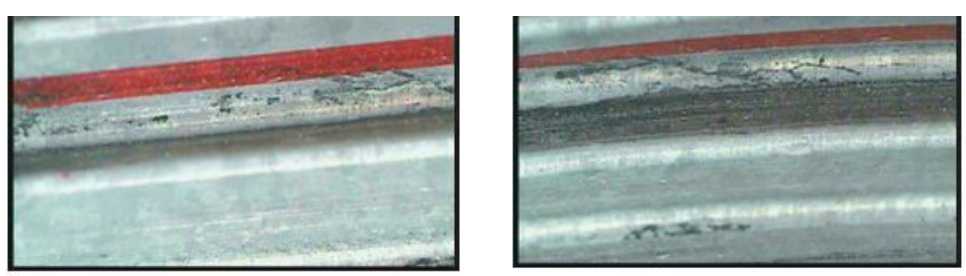

(a)
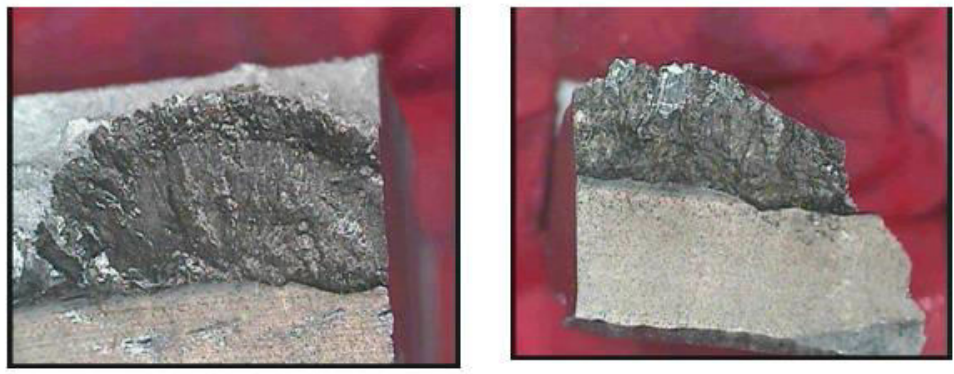

(b)

Fig. 2. (a) Cross section of the hub thread with parts of the cracks (b) open crack

Closer observation of the drilled crack surface (fig. 3) shows typical macro fractural fatigue characteristics, e.g. macro-striations (beach marks indicated by arrows, Fig. 3a), ratchet marks (arrows, Fig.3b) and semi-ellipsoids characteristic morphology (like fingernail).

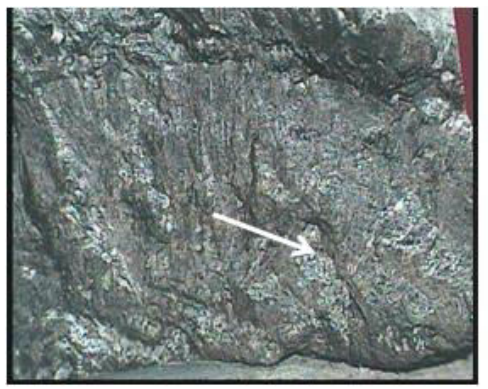

(a)

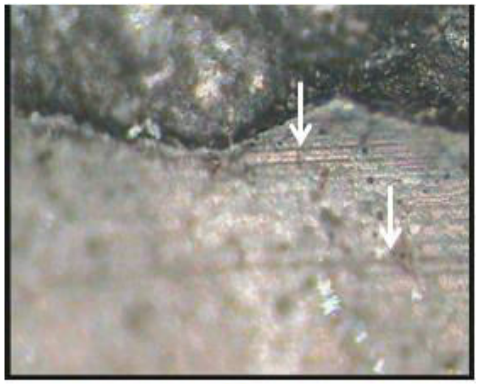

(b)

Fig. 3. Cross section of the drilled crack

\subsection{Chemical analysis}

The hubs were made of Al- alloy 2014-T6 (Table 1). The hub threads were saw tooth type with either full or cut off the tops (fig 3a). In areas where cracks were detected as well as in neighbouring areas, different colour shade of the surface was observed which is attributed to the destruction of the anodized surface layer of the threads probably caused by abrasion during assembly - disassembly (Fig. 4b). 


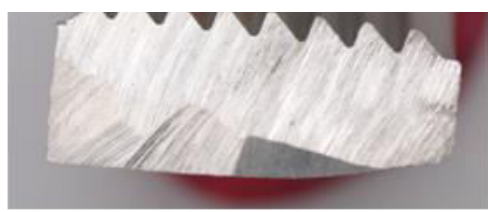

(a)

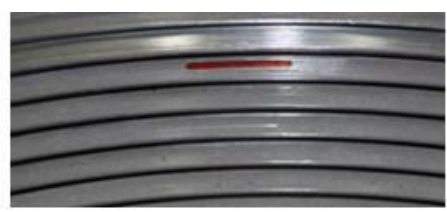

(b)

Fig. 4. The fractured hub threads

Table 1. Chemical composition of the alloy used for manufacturing the hubs

\begin{tabular}{|c|c|c|c|c|c|c|c|c|}
\hline $\mathrm{Cu}$ & $\mathrm{Mg}$ & $\mathrm{Si}$ & $\mathrm{Fe}$ & $\mathrm{Mn}$ & $\mathrm{Zn}$ & $\mathrm{Ti}$ & $\mathrm{Cr}$ & $\mathrm{Al}$ \\
\hline 3.91 & 0.47 & 0.83 & 0.29 & 0.55 & 0.06 & 0.07 & 0.01 & bal \\
\hline
\end{tabular}

Microstructural study of the hub material is shown in Fig.3 and consists of highly elongated grains with a large number of undissolved second-phase particles (5 to $10 \mu \mathrm{m}$ in size), aligned in the working direction. SEM-EDS revealed that these particles are $\mathrm{Al}_{2} \mathrm{Cu}$ (shown by white arrow in Fig. 5b) and $\mathrm{Fe}-\mathrm{Mn}-\mathrm{Al}$ (shown by black arrow in Fig. 5b) intermetallics [2].

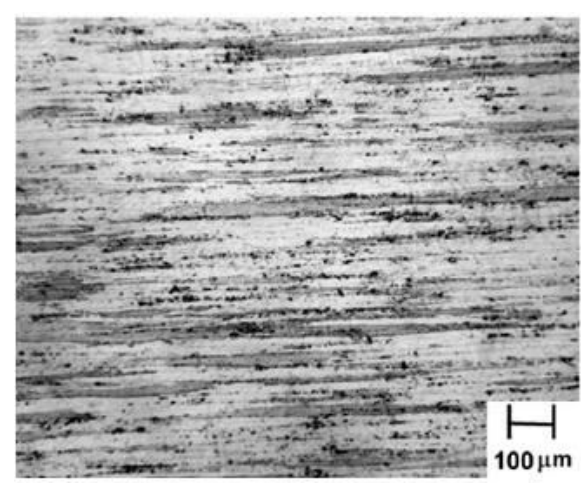

(a)

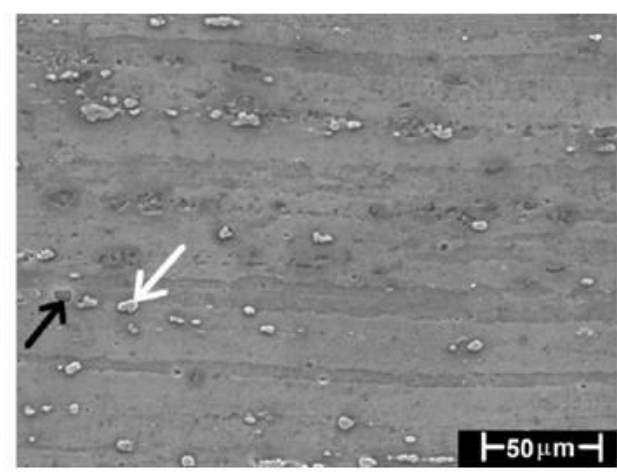

(b)

Fig. 5. Optical and SEM micrograph of the hub material

\subsection{SEM analysis of fractured surfaces}

Fig. 6 shows the micro fractural SEM examination of the area with the crack initiation point. A number of microcracks can be observed from pitting and stress corrosion cracking(SCC) of a similar nature and origin to the microcracks of the failed hub [13]. 

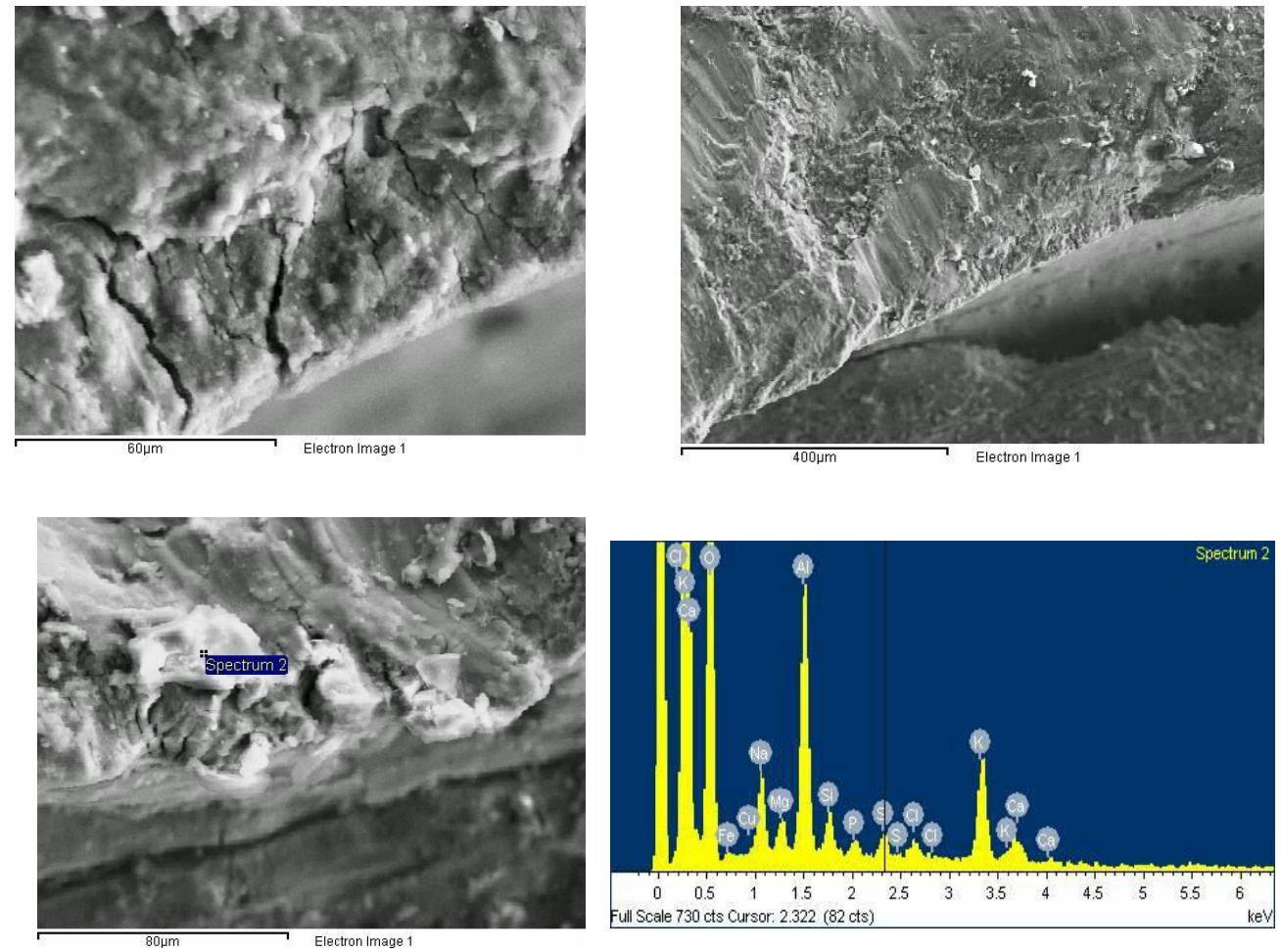

Fig. 6. Chemical microanalysis of corrosion products in the area of microcracks initiation

Chemical analysis of the corrosion products revealed the presence of $\mathrm{O}_{2}, \mathrm{Cl}, \mathrm{S}, \mathrm{K}$ and $\mathrm{Na}$ which proves that the destruction of the anodized surface film enhances pitting and stress corrosion cracking and eventually it is necessary during general inspection to check the overall situation of the protective anodizing film.

The comparative analysis of the fractured and the cracked but not fractured hub showed that failure of the hub occurs when the crack reaches a sufficient length (about $8 \mathrm{~cm}$ ) and depth (about $1.2 \mathrm{~cm}$ ). The study could not correlate the fractured striated surface with the number of cycles due to lack of data on the stress spectrum.

\section{Conclusions}

1. The fracture of an aluminum alloy (2014) propeller blade hub was investigated. During takeoffs / landings of a plane the hub detached from it bearing only one of the two blades while the other blade was detached and jettisoned and was found along with the fractured hub a distance away.

2. Visual and surface examination of the fractured hub showed that the propeller blade hub had initially cracked by a fatigue mechanism. Closer examination revealed that the crack initiated at the third and fourth spiral, close to the root of the spirals and had propagated from the inner to the outer. The multiple faces of crack growth were gradually combined to one propagating crack finally resulting to brittle fracture.

3. SEM analysis of the crack initiation points area revealed that the epicentres were created very close or/and on the spiral roots and were attributed to microcracks from corrosion pits and high stress concentration (SCC). The depth and nature of cracks, 
which caused the failure of the hub, raised concerns and led to exhaustive search for similar cracks on the other side of the hub.

4. Non Destructive Inspection (NDI) was conducted and revealed the existence of similar cracks mostly spotted in between the third and fourth spiral. The condition of the other three hubs of the plane was examined by NDI with one of them serving as a prototype. Macro-fracture and SEM analysis confirmed the presence of cracks similar to those which caused the fatigue failure of the fractured hub but at earliest stage of development.

\section{References}

1. S. Kumari, D. Satyanarayana, M. Srinivas, Failure analysis of gas turbine rotor blades, Eng. Fail. Anal., 45, 234-244 (2014)

2. D. Dhar, Fracture analysis of wheel hub fabricated from pressure die cast aluminum alloy, Theor Appl Fract Mec, 9, 45-53 (1988)

3. H. Lee, Y. Hwang, T. Kim, Failure of aircraft propeller assembly, Eng. Fail. Anal., 11, 305-312 (2004)

4. M. Kushan, S. Diltemiz, I. Sackesen, Failure analysis of an aircraft propeller, Eng. Fail. Anal., 14, 1693-1700 (2007)

5. T. Carter, Common failures in gas turbine blades, Eng. Fail. Anal., 12, 237-247 (2005)

6. B. Kamsu Foguem, Knowledge based support in non-destructive testing for health monitoring of structures, in Advanced Engineering Informatics (Elsevier), 26, 859-869 (2012)

7. B. Kosec, G. Kovacic, L. Kosec, Fatigue crack of an aircraft wheel, Eng. Fail. Anal., 9, 603- 609 (2008)

8. J. Sherwood, J. Ayres, T. Gross, "An investigation of tire wheel interface loads using ADINA, Computers and Structures, 56, 377-387 (1995)

9. J. Martin, J. G. Gil, E. Sanchez, Non- Destructive techniques based on eddy current testing, Sensors, 11, 2525-2565 (2011)

10. T. Nauman, A. Siddiqui, M Subair Khan, A. Munir, K. Deen, M. Amin, Failure investigation of wheel gear hub assembly of an aircraft, Eng. Fail. Anal., 22, 73-82 (2012)

11. Goodrich, Aircraft wheels and brakes «Component Maintenance Manual», Revision 7, September (2008)

12. J. Jose, Analysis of Aircraft Wheel Hub Assembly Using NDT Techniques, International Advanced Research Journal in Science, Engineering and Technology, 3, 17-20 (2016)

13. H. Mae, X. Teng, Y. Bai, T. Wierzbicki, Calibration of ductile fracture properties of a cast aluminium alloy, Mater Sci. Eng. A 459, 156-166 (2007) 